\title{
LEARNING CURVE APPLICATION TO SPACE SHUTTLE PROCESSING SIMULATIONS
}

\author{
Michael G. Madden \\ United Space Alliance, LLC \\ Kennedy Space Center \\ 8550 Astronaut Blvd. \\ Cape Canaveral, FL 32920, U.S.A.
}

\begin{abstract}
Traditional learning curves were pioneered by T.P. Wright in 1936, with the idea that improvements in labor-hours to manufacture an airplane could be described in a mathematical pattern. This paper will show that this concept of learning curve improvements to production metrics can be applied based on cumulative time, rather than volume of production, for one-of-a-kind applications, such as space shuttle flights, where production quantities are very limited. Policy and process changes can also be observed in production data, and the learning curve is useful in the prediction of future trends. Past data from space shuttle processing is demonstrated to fit this new definition, and prediction of future process metrics is explored. Once the learning curve is time-based, simulation can be applied to model the system and enhance the prediction effort for future process metrics.
\end{abstract}

\section{INTRODUCTION}

For the purpose of this paper, a Space Shuttle processing flow is defined as all the work done to process a Space Shuttle Orbiter for each individual mission. The timeframe encompasses the work done beginning at Orbiter Landing from the prior mission, post-mission de-servicing and premission processing in the Orbiter Processing Facility (OPF). There is additional effort required to mate the Orbiter to the External Tank and Solid Rocket Boosters in the Vehicle Assembly Building (VAB), and integrated vehicle and pre-launch processing operations at the launch pad, right up to launch time, but these tasks are not part of this simulation model. The learning curve application described herein deals predominantly with the OPF portion of the Space Shuttle processing flow as this portion of effort has the highest variability in the total process from landing to launch.

Process performance metrics for one-of-a-kind production systems are more complex and variable than the more conventional mass production operations. The unique nature of the processes results in some variability that is not found in traditional production lines. While working with data for the Space Shuttle Program and trying to develop methods to predict future process timelines, analysis of past processing was performed for use in future estimations. The process is very dynamic and it was very difficult to directly observe trends in the historical data. During the completion of a Lean-6-Sigma (L6S) Black Belt project, linear regression was applied to the data. The regression attempted to predict OPF processing days by using known task durations planned; quantities of process paperwork; shifts per week, or planning density; and many other postflow measurements. Even after attempting many different transformations, there was a large residual variability that was yet to be understood in the analysis of ground processing days per space shuttle mission.

After the Columbia tragedy, management recognized there would be a change in the production metrics and wanted to understand if an analysis of post-Challenger data could provide some insight into a good predictor for post Columbia Return-to-Flight (RTF) timelines. Retrieving good data for an 18-year old process that was a difficult research effort, but good sources of data for the preChallenger processes were eventually identified. A predominant visualization was that as flows went along, production metrics decreased. Figure 1 illustrates this notionally, as processing days, the production metric in this case, decrease with time, and subsequently increase with a processing change, only to begin the learning and decreasing process over for the new set of requirements.

The author also noted that after major business practice policy changes, such as a new contractor taking over the effort or a major program process revision after the Challenger incident, a sharp initial increase could be seen followed by a return to the gradual reduction of metrics with the sequential performance of each mission. This trend was not yet quantifiable, but was believed to be related to the traditional "Learning Curve" theory. Traditional learning curves were pioneered by T.P. Wright in 1936, with the idea that improvements in labor-hours to 
manufacture an airplane could be described in a mathematical pattern that forms a straight line on a log-log graph. A more thorough evaluation of this theory was needed to confirm the relationship.

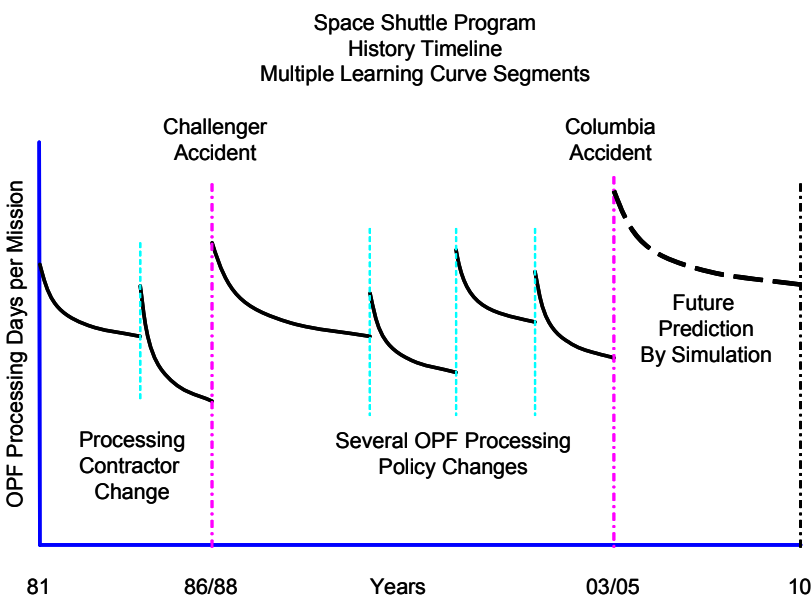

Figure 1: Shuttle Program Processing Data Timeline to Illustrate Multiple Learning Trends (Notional Data)

Space Shuttle processing from one flow to the next is somewhat repetitive, and for the most part similar in level of detail from one flow to the next. However, there are exceptions. For example, when a new space shuttle is first flown, the checks are more extensive, and after a major modification or an overhaul period (long down time for more extensive inspections), the flows are not "nominal". This paper will not get into the details of nominal vs. nonnominal flows, except to state the fact that in a given set of data of approximately 80 flows, there might be 20 that are considered non-nominal. When analyzing nominal flows for the purposes of learning curves and trend analyses, the production values are not sequential. The flows being analyzed as 1, 2 and 3 might have been flows 1, 4, and 6 if several off-nominal flows were intermixed. It was the consideration of this very detail and the notion that even though off-nominal flows were not being analyzed in the trend data, the time and process was going on for these flows and that "Learning" and process improvement might still be ongoing during the other flows, that led to the usage of elapsed time rather than number of units produced for the learning curve methodology.

\section{METHODOLOGY}

Another form of the learning curve methodology was needed to fit this data for determination of the Learning Rates of Space Shuttle processing efforts; therefore the concept of cumulative time working on the process was considered. The assumption is that during the continued time, the process is being worked even if the non-nominal flow is not counted in the final metric. By starting with the first flow as month 1 , since the log-log approach does not accept values of zero, the launch date was used to calculate accumulated months of learning per flow. model:

A traditional Learning Curve uses the following

$$
Y=A^{*} X^{B}
$$

Where $\mathrm{Y}$ is the value to be estimated, $\mathrm{A}$ is the initial value for the first unit of production, $\mathrm{X}$ is the unit number in a sequential series of produced items, and $\mathrm{B}$ is a line slope constant that is related to the rate of improvement in the process with additional levels of production.

$\mathrm{B}$ is literally equal to the following:

$$
B=\frac{\ln (L P)}{\ln (2)},
$$

where LP is Learning Percentage and RP is Rate of Improvement:

$$
L P=1-R P .
$$

The traditional learning curve states that an improvement of the rate indicated above can be expected each time the quantity of production doubles (per the $\ln (2)$ term).

NASA has a website explaining this concept for cost estimating, and several traditional industrial types are identified with typical and expected learning curves to their specific process (<http://www1.jsc.nasa.gov/ bu2/learn.html $>$ ).

In a unique production process, such as space shuttle ground processing for each mission, where the nominal flows to be estimated are not sequential, the alternative to the traditional learning curve proposed is a value of $\mathrm{X}$ to be the cumulative months of learning from the initial process to some defined date in each process. Since launch dates are used for future schedule analysis, an arbitrary date for each flow in the historical data was taken as the launch date. model:

The Time-Based Learning Curve utilizes the following

$$
Y=A^{*} T^{B}
$$

where $\mathrm{T}$ is the Cumulative Months in our case of the learning process per shuttle flow. This change to the methodology of learning curve analysis would revise the statement to be that for shuttle processing, a rate of improvement would be expected each time the number of months doubles from one flow to the next. This assumes that processing and learning is on-going; a work stoppage or down period could not be considered as accumulated time for the purposes of a learning curve analysis. 


\section{DATA ANALYSIS}

Several sets of data exist. Using the days per flow data, and taking into account the period of processing before the Challenger accident, we have 19 data points as shown in Table 1.

Table 1: Pre-Challenger Data

\begin{tabular}{|c|c|c|c|c|c|}
\hline \multicolumn{7}{|c|}{ OPF Processing Work Days } \\
\hline Seq & Flt. & $\begin{array}{c}\text { STS } \\
\text { No. }\end{array}$ & Launch Date & $\begin{array}{c}\text { Time } \\
\text { Mo. }\end{array}$ & $\begin{array}{c}\text { Work } \\
\text { Days }\end{array}$ \\
\hline 1 & 2 & 2 & 12-Nov-81 & 1.0 & 103 \\
\hline 2 & 3 & 3 & 22-Mar-82 & 5.3 & 70 \\
\hline 3 & 4 & 4 & 27-Jun-82 & 8.6 & 42 \\
\hline 4 & 5 & 5 & 11-Nov-82 & 13.1 & 57 \\
\hline 5 & 7 & 7 & 18-Jun-83 & 20.4 & 34 \\
\hline 6 & 8 & 8 & 30-Aug-83 & 22.9 & 27 \\
\hline 7 & 10 & $41-\mathrm{B}$ & 03-Feb-84 & 28.1 & 67 \\
\hline 8 & 11 & $41-\mathrm{C}$ & 06-Apr-84 & 30.2 & 32 \\
\hline 9 & 13 & $41-\mathrm{G}$ & 05-Oct-84 & 36.3 & 69 \\
\hline 10 & 14 & $51-\mathrm{A}$ & 08-Nov-84 & 37.4 & 37 \\
\hline 11 & 15 & $51-\mathrm{C}$ & 24-Jan-85 & 40.0 & 35 \\
\hline 12 & 16 & $51-\mathrm{D}$ & 12-Apr-95 & 42.6 & 31 \\
\hline 13 & 17 & $51-\mathrm{B}$ & 29-Apr-85 & 43.1 & 33 \\
\hline 14 & 18 & $51-\mathrm{G}$ & 17-Jun-85 & 44.8 & 38 \\
\hline 15 & 19 & $51-\mathrm{F}$ & 29-Jul-85 & 46.2 & 43 \\
\hline 16 & 20 & $51-\mathrm{I}$ & 27-Aug-85 & 47.1 & 30 \\
\hline 17 & 22 & $61-\mathrm{A}$ & 30-Oct-85 & 49.3 & 40 \\
\hline 18 & 23 & $61-\mathrm{B}$ & 26-Nov-85 & 50.2 & 27 \\
\hline 19 & 25 & 51-L & 28-Jan-86 & 52.3 & 35 \\
\hline
\end{tabular}

The curve shown in Figure 2 represents the traditional method of presenting learning curve data. It is shown in sequential order and each flight is spaced by a value of 1 in the $\mathrm{X}$ direction. The fact that nominal flows were not flown one right after another is not a factor in this version. The Values for A and B are shown as 71.665 and -0.3107 . Using the formulas 1-3 above this equates to a rate of learning of $36 \%$. This curve does not properly account for the time between missions that are not sequential and that the learning and improvements to our process are ongoing.

The plot shown in Figure 3 accounts for this time differential by using the timing months $(\mathrm{T})$ from Table 1 . The time based curve is a better fit as indicated by the higher $R^{2}$ value. It indicates a lower rate of learning, at $32 \%$, and the initial value is more closely related to the actual first workday value. Also notice in Figure 3, that there appears to be two different curves within this data set, based on the noisy data and higher points at the 27-35 month flow mark. One way to actually explore this is to plot the log values of days by the log values of months and look for the straight lines, line segments and natural breaks in the data. See Figure 4 for this visualization.

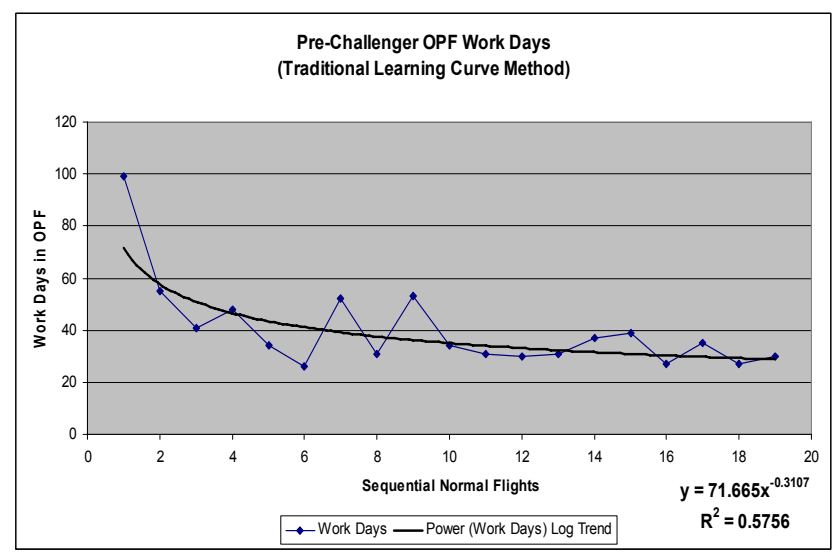

Figure 2: Traditional Learning Curve Method (Sequential Numbers) to Pre-Challenger Accident Data

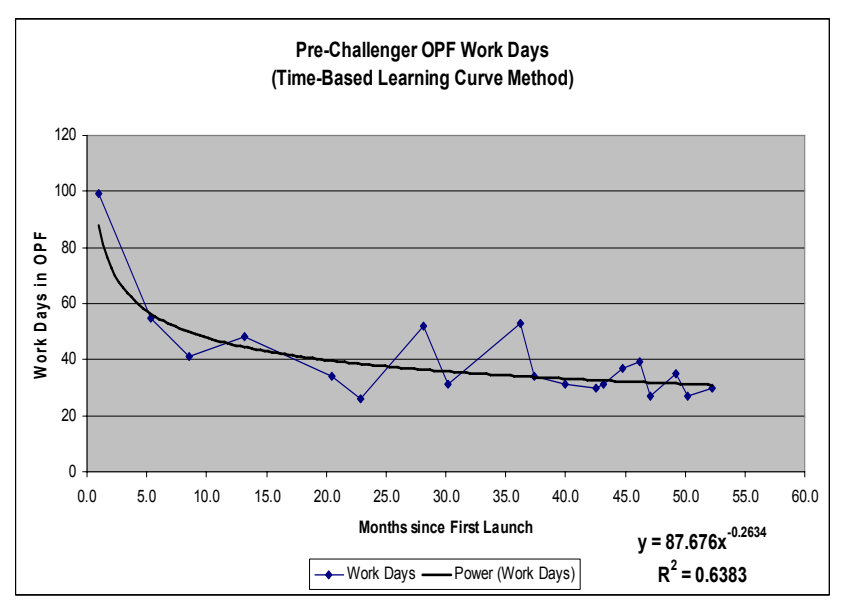

Figure 3: Time-Based Learning Curve Method (Cumulative Months) for Pre-Challenger Data

Figure 4 shows an overall trend line, but there appears to be two distinct curves (straight line estimates) that do not actually follow this full data set trend line. The equation in this graph is of a slightly different format since the curves are log values, but we see the same $R^{2}$ and the same $B$ value. However, if we were to break this line into two segments, and plot the individual trends, we get the following graph shown in Figure 5.

This indicates that maybe there was some form of processing or business practice change during the period of data, from November 1981 to January 1986. If we review the Shuttle Program history during the time frame of this split between the 2 lines (August 1983 to February 1984), a significant business practice change did occur. The processing before August 1983 was performed by North American Rockwell, the contractor who designed and built the Space Shuttle. The learning rates for these two different curves are calculated to be $42 \%$ and $63 \%$ respectively. 


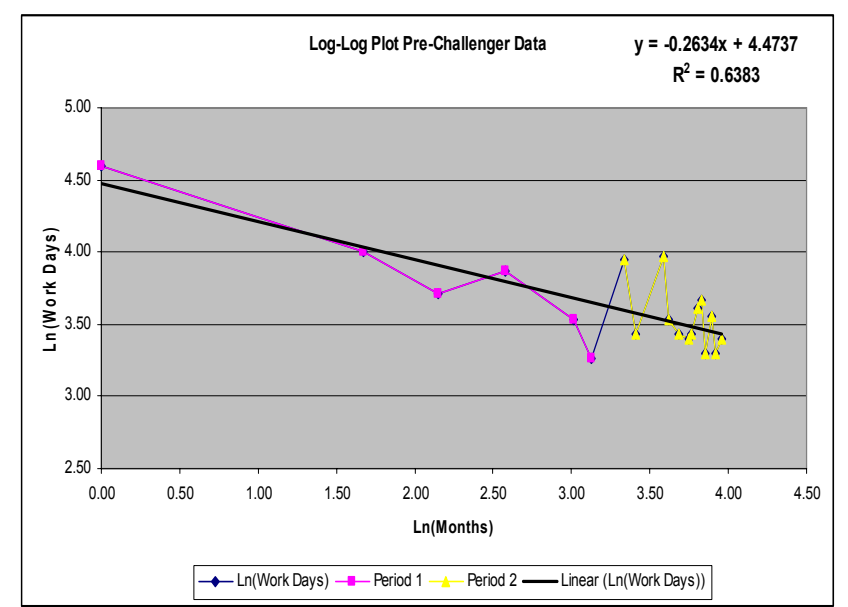

Figure 4: "Log-Log" Plot of Time-Based Learning Curve Method for Pre-Challenger Accident Data

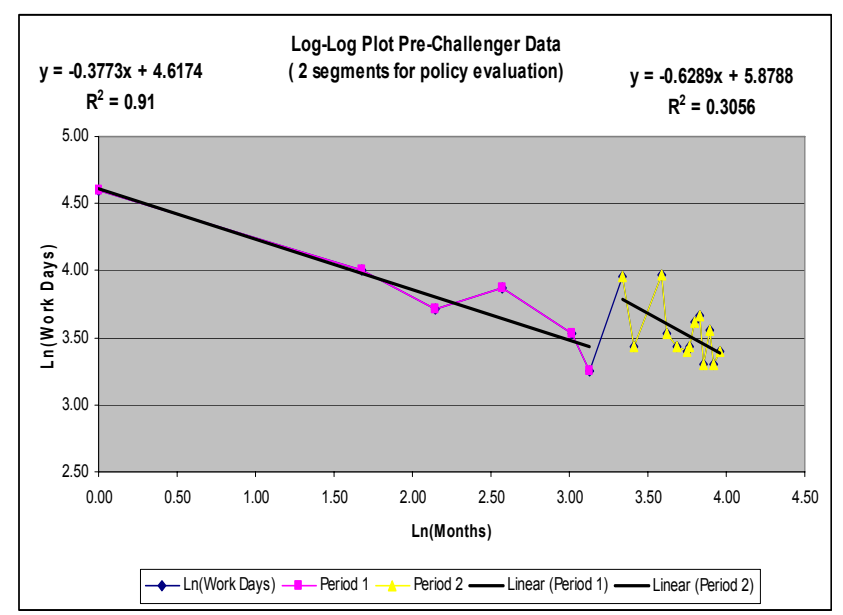

Figure 5: Log-Log Plot with 2 Linear Trend Estimates of Learning Curves for Pre-Challenger Data

During Late 1983 and 1984 a new contract was won by Lockheed Space Operations Company to perform Space Shuttle processing. During this transition many people working at $\mathrm{KSC}$ were given the opportunity to move from Rockwell to Lockheed under the new contract, therefore, the technician and engineering workforce remained largely the same. Changes to personnel were mostly seen in the higher levels of management, so the learning curve of work effort after transition to Lockheed responded more quickly to the new environment. The fact that many of the same people were performing on both sides of the transition may account for the high learning rates after transition.

After the Challenger accident in early 1986, the Rogers' Commission was convened to review preChallenger processing data for the express purpose of determining the events that led up to and the primary cause of the accident. One criticism from the group was that there appeared to have been a great deal of schedule pressure and that work was being rushed to meet shorter and shorter mission turnaround timelines. (Rogers \& et al., 1986) The data shown in the log-log plot appears to validate that processing times had decreased a great deal, since a learning rate of $63 \%$ is unheard of in most industries. The $42 \%$ and $32 \%$ combined rates are also very high relative to other shuttle learning rate data. Although the primary cause of the accident was determined to be O-ring failure in the Solid Rocket Booster (SRB), the schedule pressure criticism received a great deal of attention, and resulted in significant post-Challenger processing requirements changes.

Given that the Shuttle Program took stock of itself after the Challenger Accident, revised many business practices, made processing more rigorous, and increased requirements, an interesting research question followswhat does the after-accident data show? An initial observation is that post-Challenger flows are longer, starting in the 105 day range vs. the 80 day range prior to the Challenger accident. The rate of learning is also calculated to be lower at $16 \%$ for these 23 missions. See Figures 6,7 and Table 2 for the data set for this graph. This data may be indicative of several different processing business practices shown notionally in Figure 1, which may have effected OPF work days. So a closer look at the Log-Log plots was performed and is shown in Figure 7.

This process is highly variable, but it still can be seen that something changed in the 1990-1991 time frame. Again, a review of processing practices was performed and it should be noted that there was an effort to go from 70 to 90 day flows down to 50 and 70 day OPF flows during this time frame. The learning rates for the segments are $8 \%$ and $43 \%$ respectively. The $43 \%$ is after the policy change with the same people working but to a different set of rules. Again, we see a very high value, which may have been a leading indicator of another trend to be monitored in the Space Shuttle Program and business practices area.

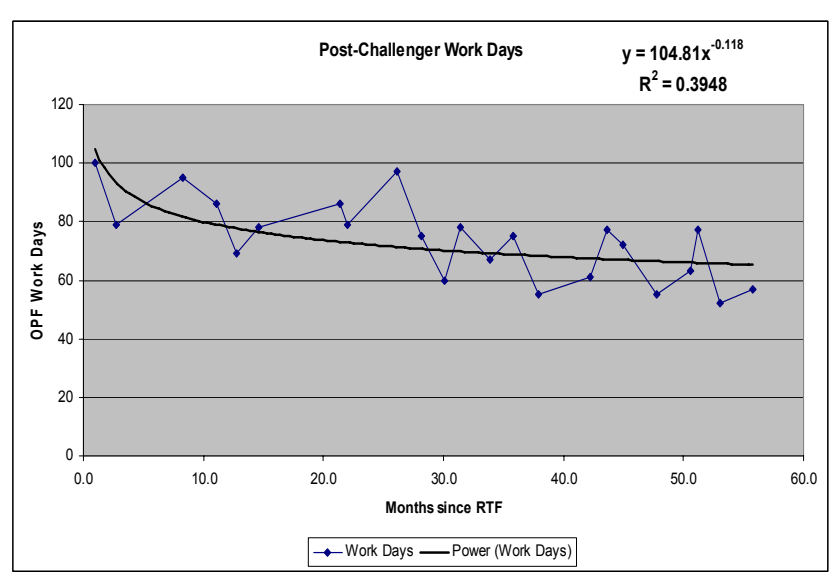

Figure 6: Post-Challenger Time-Based Learning Curve Method for 23 Nominal Duration OPF Flows 


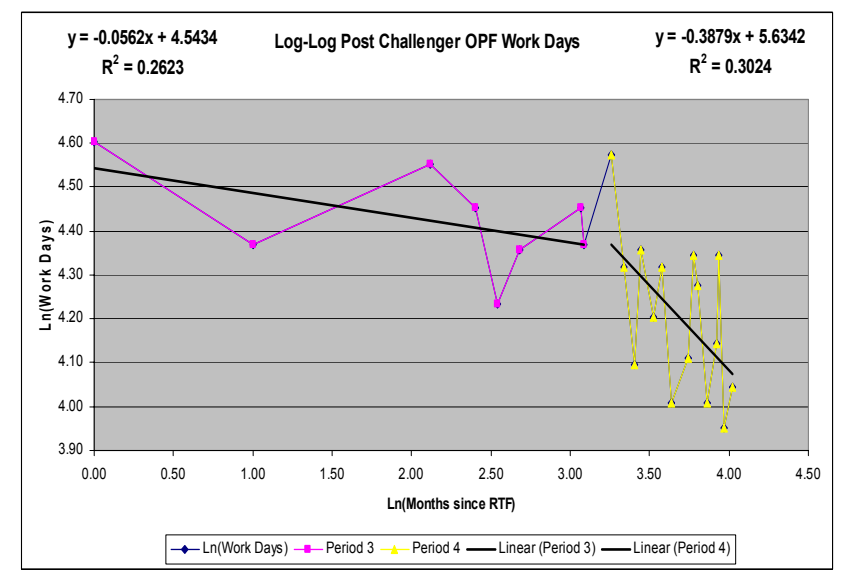

Figure7: Log-Log Plot of Post-Challenger Flows to Identify Business Practice Changes of OPF Processing Days

Table 2: Post Challenger Data

\begin{tabular}{|c|c|c|c|c|c|}
\hline \multicolumn{6}{|c|}{ OPF Processing Work Days/Calendar Days } \\
\hline $\begin{array}{c}\text { Seq. } \\
\text { Order }\end{array}$ & $\begin{array}{c}\text { Flt. } \\
\text { Order }\end{array}$ & $\begin{array}{c}\text { STS } \\
\text { No. }\end{array}$ & $\begin{array}{c}\text { Launch } \\
\text { Date }\end{array}$ & $\begin{array}{c}\text { Time } \\
\text { Months }\end{array}$ & $\begin{array}{c}\text { Work } \\
\text { Days }\end{array}$ \\
\hline 1 & 28 & 29 & 13-Mar-89 & 1.0 & $100 / 106$ \\
\hline 2 & 29 & 30 & 04-May-89 & 2.7 & $79 / 87$ \\
\hline 3 & 31 & 34 & 18-Oct-89 & 8.3 & $95 / 97$ \\
\hline 4 & 33 & 32 & 09-Jan-90 & 11.1 & $86 / 87$ \\
\hline 5 & 34 & 36 & 28-Feb-90 & 12.7 & $69 / 81$ \\
\hline 6 & 35 & 31 & 24-Apr-90 & 14.6 & $78 / 88$ \\
\hline 7 & 37 & 38 & 15-Nov-90 & 21.4 & $86 / 87$ \\
\hline 8 & 38 & 35 & 02-Dec-90 & 22.0 & $79 / 79$ \\
\hline 9 & 39 & 37 & 05-Apr-91 & 26.1 & $97 / 108$ \\
\hline 10 & 41 & 40 & 05-Jun-91 & 28.1 & $75 / 75$ \\
\hline 11 & 42 & 43 & 02-Aug-91 & 30.1 & $60 / 61$ \\
\hline 12 & 43 & 48 & 12-Sep-91 & 31.4 & $78 / 80$ \\
\hline 13 & 44 & 44 & 24-Nov-91 & 33.9 & $67 / 68$ \\
\hline 14 & 45 & 42 & 22-Jan-92 & 35.8 & $75 / 77$ \\
\hline 15 & 46 & 45 & 24-Mar-92 & 37.9 & $55 / 66$ \\
\hline 16 & 49 & 46 & 31-Jul-92 & 42.2 & $61 / 63$ \\
\hline 17 & 50 & 47 & 12-Sep-92 & 43.6 & $77 / 78$ \\
\hline 18 & 51 & 52 & 22-Oct-92 & 45.0 & $72 / 73$ \\
\hline 19 & 53 & 54 & 13-Jan-93 & 47.7 & $55 / 63$ \\
\hline 20 & 54 & 56 & 08-Apr-93 & 50.6 & $63 / 74$ \\
\hline 21 & 55 & 55 & 26-Apr-93 & 51.2 & $77 / 93$ \\
\hline 22 & 56 & 57 & 21-Jun-93 & 53.0 & $52 / 63$ \\
\hline 23 & 57 & 51 & 12-Sep-93 & 55.8 & $57 / 61$ \\
\hline
\end{tabular}

Figure 8 shows over 150 months of nominal flow data, and you can see there are several segments where a linear estimate will diverge or where the learning was "reset". These resets seem to correspond with changes in the planning and scheduling of OPF work flow periods. At different times over the course of the program, business decisions were made in cooperation with NASA to either slow down or increase the pace of flights. It is apparent that after a business practice change there is always some amount of continued "learning curve" trends to the data. Linear trends are better shown by separating each individual "Learning time period" into its own dataset and resetting the time pe- riod start to each group's "reset point" and recalculating the time-based $\mathrm{T}$ value to the new first month value. However, one must look initially at the entire set to find the break-points or linear segments. These segments are somewhat arbitrary and the author used some subject matter expertise to identify change times and to split the linear trends.

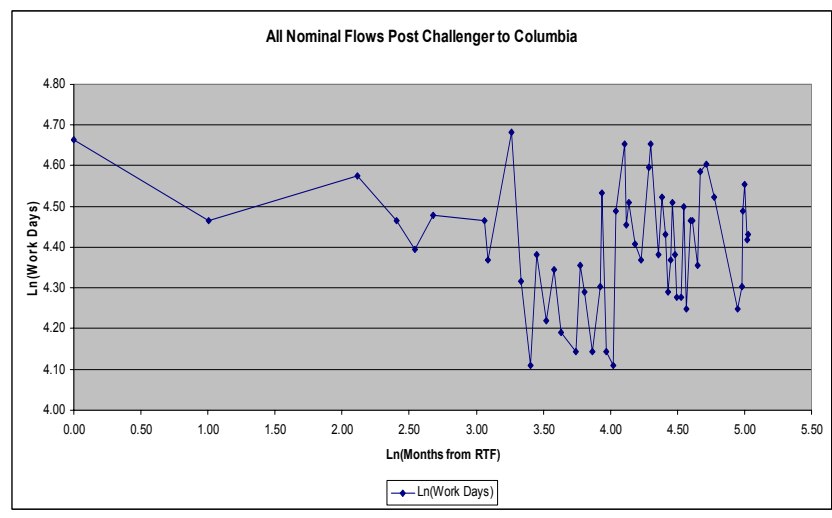

Figure 8: Long Term (12-plus years) Nominal Flow Data Post-Challenger for Evaluating Learning Curve and Policy Changes

A different approach for visualizing the same data reveals new segments as shown in Figure 9. This graph represents the entire period between the Challenger incident and the Columbia incident as shown notionally in Figure 1. One must look very closely to see the five different line segments and business practice changes that can be seen in the data from the 1988 thru 2002 time frame.

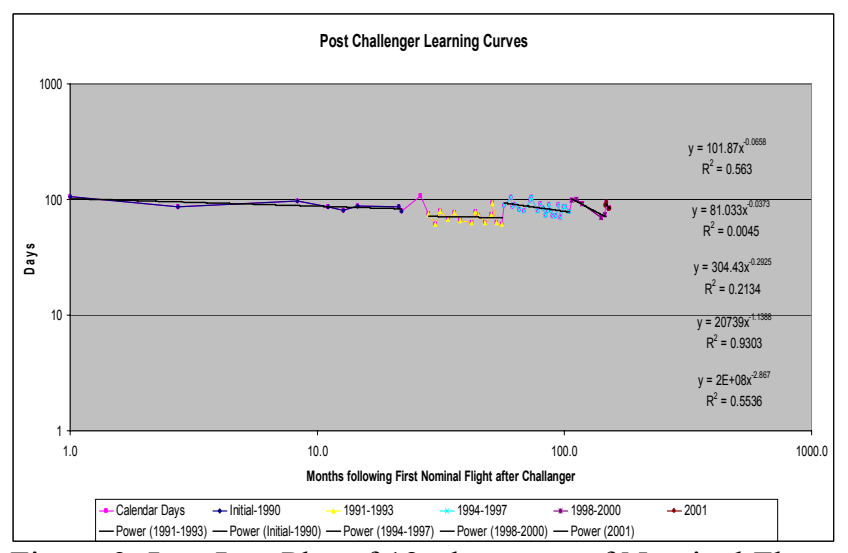

Figure 9: Log-Log Plot of 12-plus years of Nominal Flows Post-Challenger to Identify Policy and Learning Curve Transitions

\section{APPLICATION TO FUTURE PREDICTIONS}

Presently there are less than 20 planned flights left in the Shuttle Program. (Cates and Mollaghasemi 2005a) Traditional planning used deterministic dates for a manifest of 
future scheduled flights. These Shuttle planning manifests have been shown in 6 month, 18 month and 5 year versions. If the Space Shuttle is to be retired in the end of 2010 per the vision of President Bush (Bush 2004), then as of Dec 2006 there are only about 48 months left in the Space Shuttle Program. Management has recently embraced a more stochastic approach to the planning. Simulation models have been developed to predict the probability of meeting a certain manifest of flights in a certain time period (Cates and Mollaghasemi 2005a, Cates and Mollaghasemi 2005b).

The added requirements from the Columbia Report to the Space Shuttle process have increased the flow timelines (Gehman et al. 2003). It is difficult to predict the degree to which the flow timelines will be increased until data is obtained for at least a few flows after the Columbia accident. However, with this new time-based learning curve methodology and some simple spreadsheet-based simulation we can attempt to determine the effect that the maximum number of flights possible before 2010 and changes to the processing policy will have on the OPF timelines.

USA and NASA are evaluating and predicting between 110 and 140 days currently to complete an OPF flow. To evaluate this variable and to understand how many missions can be expected to be completed by the 2010 deadline, an Excel spreadsheet-based simulation (Seila 2005) has been created to demonstrate to the Shuttle Program management, the effects of 140-day flows and the sensitivity of this completion to 120-day or 170-day flows if the initial estimates are do not hold up. The assumption is that, regardless of this value, the process will improve with time, as have all other OPF Flows once a business practice is established and people get into a routine for performing the process.

Given that the future flight manifest will have unevenly distributed flight spacing, a random spacer was developed for this spreadsheet simulation. The random spacer for flights needs the theoretical minimum launch spacing given three vehicles, and the timelines associated with the major processes and the variability known for these types of processes in the Space Shuttle Program. See Table 3 for this tabulation and analysis.

The ranges of launch spacing varies from 2.6 to 3.1 months per launch and this is consistent with maximum flight rates we have achieved in the recent history of the shuttle program (between 4-6 flights per year which is 2-3 months per launch).

The new limitations of Daylight Launch and Beta Angle Window constraints when combined with the 140 day OPF flow reduces our theoretical maximum flight rate to about 4.3 flights per year at best. Hence, the reduction of OPF work days as related to learning curve will actually improve the potential maximum flight rate (Cates and Mollaghasemi 2005a).
Table 3: Flight Rate Analysis for Future Simulation

\begin{tabular}{|c|c|c|c|c|c|c|c|c|}
\hline \multirow{2}{*}{ 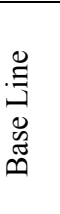 } & \multicolumn{5}{|c|}{ Site Process Timelines } & \multirow[b]{2}{*}{$\overbrace{\overparen{\overbrace{}}}^{n}$} & \multicolumn{2}{|c|}{$\begin{array}{c}\text { Min } \\
\text { Spacing }\end{array}$} \\
\hline & $\frac{1}{2}$ & $\sum_{>}^{\frac{n}{4}}$ & 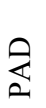 & $\frac{ \pm}{L}$ &  & & 忿 & $\dot{\rho}^{\dot{\rho}}$ \\
\hline $\begin{array}{l}120 \\
\text { Day }\end{array}$ & $\begin{array}{c}12 \\
0\end{array}$ & 5 & 20 & 10 & & 155 & 51.7 & 1.7 \\
\hline Var & 15 & 3 & 10 & 3 & 45 & 231 & 77.0 & 2.6 \\
\hline $\begin{array}{l}140 \\
\text { Day }\end{array}$ & $\begin{array}{c}14 \\
0\end{array}$ & 5 & 20 & 10 & & 175 & 58.3 & 1.9 \\
\hline Var. & 15 & 3 & 10 & 3 & 45 & 251 & 83.7 & 2.8 \\
\hline $\begin{array}{l}170 \\
\text { Day }\end{array}$ & $\begin{array}{c}17 \\
0\end{array}$ & 5 & 20 & 10 & & 205 & 68.3 & 2.3 \\
\hline Var & 15 & 3 & 10 & 3 & 45 & 281 & 93.7 & 3.1 \\
\hline
\end{tabular}

The spreadsheet simulation shown in Table 4 and Figure 10 shows one set of results from the simulation of the effects of learning curves on the post-Columbia OPF Processing flow timelines.

In this example, the timeline is formed by randomly spaced launches from the spacing analysis, and the predictive formula of equation 4 is used to predict the OPF processing days. A RP value of 7\% learning was used, indicative of production taking $93 \%$ of the previous value every time the cumulative months double from the start of the "Learning Period". The smooth results of the effect of Learning Curves on the future processing predictive simulation are shown in Figure 10.

Table 4: Post Columbia Future Simulation Data

\begin{tabular}{|c|c|c|c|c|}
\hline Flight & $\begin{array}{c}\text { Time } \\
\text { (Months) } \\
\text { (Random) }\end{array}$ & $\begin{array}{c}\text { OPF } \\
\text { Work } \\
\text { Days }\end{array}$ & $\begin{array}{c}\text { Running } \\
\text { Average }\end{array}$ & $\begin{array}{c}\text { OPF Days } \\
\text { Percentage } \\
\text { of Flow Du- } \\
\text { ration }\end{array}$ \\
\hline 1 & 1 & 140 & 140 & $56 \%$ \\
\hline 2 & 3.9 & 121 & 131 & $48 \%$ \\
\hline 3 & 6.9 & 114 & 125 & $45 \%$ \\
\hline 4 & 10.2 & 110 & 121 & $40 \%$ \\
\hline 5 & 13.2 & 107 & 119 & $38 \%$ \\
\hline 6 & 16.6 & 104 & 116 & $36 \%$ \\
\hline 7 & 20.0 & 102 & 114 & $35 \%$ \\
\hline 8 & 23.2 & 101 & 112 & $34 \%$ \\
\hline 9 & 26.7 & 99 & 111 & $33 \%$ \\
\hline 10 & 30.3 & 98 & 110 & $32 \%$ \\
\hline 11 & 33.9 & 97 & 109 & $30 \%$ \\
\hline 12 & 36.9 & 96 & 107 & $31 \%$ \\
\hline 13 & 40.2 & 95 & 107 & $32 \%$ \\
\hline 14 & 43.6 & 94 & 106 & $32 \%$ \\
\hline 15 & 47.1 & 94 & 105 & $30 \%$ \\
\hline 16 & 50.6 & 93 & 104 & $30 \%$ \\
\hline 17 & 54.3 & 92 & 103 & $29 \%$ \\
\hline 18 & 57.5 & 92 & 103 & $30 \%$ \\
\hline 19 & 60.9 & 91 & 102 & $30 \%$ \\
\hline
\end{tabular}




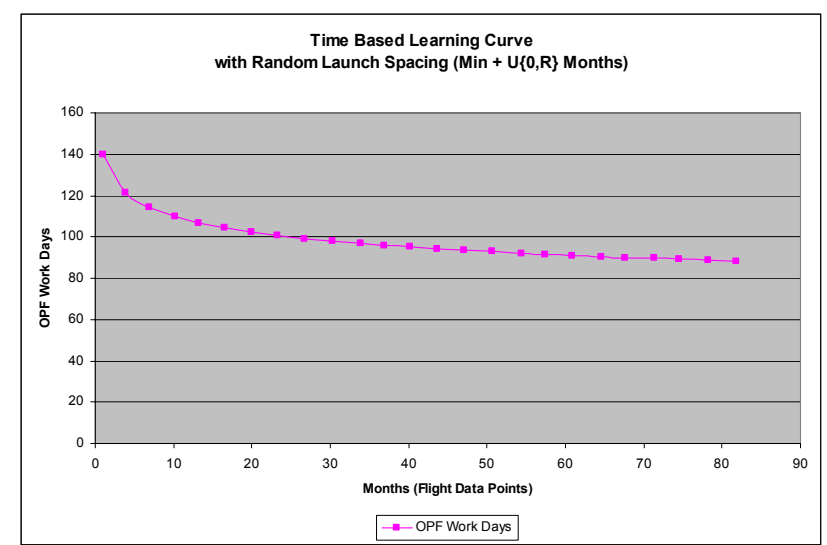

Figure 10: Effect of Learning on Future OPF Processing Post-Columbia Based on 140 day First Nominal Flow

\section{DISCUSSION OF RESULTS}

OPF work days represent one part of a highly variable process. Reviewing the data since the Challenger incident, the workdays have been $50 \%$ on average of the total cycle days between successive launches of the same vehicle. Using the spreadsheet simulation, the 140 day initial OPF Work Day estimate, and a 7\% Learning Rate based on post challenger data, the remaining 16 missions will have an OPF work day content of $36 \%$ which is lower than the program average to date. This indicates that this OPF flow duration and maximum flight rate do not conflict and the manifest can feasibly be met.

The 140-day patterns will require the launch rate to get to a value of 2.8 to 3.8 months per launch or 3.2 to 4.3 flights per year. However, the first two to three missions will be a strain in excess of $50 \%$ OPF work days per flow, due to longer the longer duration OPF flows. All of these values seem to be within the previous operational limits of the Space Shuttle Program. (Cates and Mollaghasemi 2005a)

If the estimate for OPF days is low and it goes to the higher value of 170-days initially, the percentage of OPF work days increases to $44 \%$ on average. However, the first few missions of five to six, while the learning rate has not greatly reduced the 170 day value, run in the 67 to $50 \%$ range. This has a lower probability of success in meeting the manifest rate needed.

If the program can meet the lower value of 110 to 120 day OPF processing timelines initially, all of the data for the remaining Shuttle Program flights would fall well within previously demonstrated historical limits. This would ensure a high degree of confidence in meeting the remaining manifest to complete the International Space Station (ISS) build and close out the Space Shuttle Program flights.

\section{CONCLUSIONS}

Traditional learning curves have a few limitations which do not lend themselves perfectly to low volume and oneof-a-kind production scenarios such as Space Shuttle flight processing. This paper has demonstrated that a time-based adaptation of the learning curve method can be applied to this lower volume production with slightly increased accuracy. The log-log curves show the linear trends and changes in the metric being evaluated. With a time-based adaptation of the learning curve, the changes in slopes of the regression lines can be tied to historical changes in business practices and the subsequent reset and continuation of the learning process. Time-based learning curves allow for data outliers to be removed from the dataset without having the sequential change affect the resultant learning rate estimate. They also allow for the learning that occurred during the outlier process to be accounted for in the final estimation of the learning rates.

Recognizing that a given process follows a learning curve trend is very useful in making predictions and estimations in future production metrics. Using historical improvement rates as the basis of the estimate is more effective than an anecdotal concept of improvement of the process with time. The time-based learning curve method lends itself to a mathematical prediction solution for this unique process and its production metrics.

\section{GLOSSARY}

$\begin{array}{ll}\text { CAIB } & \text { Columbia Accident Investigation Board } \\ \text { CEV } & \text { Crew Exploration Vehicle } \\ \text { ET } & \text { External Tank } \\ \text { ISS } & \text { International Space Station } \\ \text { KSC } & \text { Kennedy Space Center } \\ \text { L6S } & \text { Lean Six Sigma } \\ \text { NASA } & \text { National Aeronautical and Space } \\ & \text { Administration } \\ \text { OPF } & \text { Orbiter Processing Facility } \\ \text { RTF } & \text { Return to Flight } \\ & \text { (Flight after an accident) } \\ \text { SME } & \text { Subject Matter Expert } \\ \text { SRB } & \text { Solid Rocket Booster } \\ \text { USA } & \text { United Space Alliance } \\ & \text { (Space Flight Operations Contractor) } \\ \text { VAB } & \text { Vehicle Assembly Building }\end{array}$

\section{REFERENCES}

Bush, G. W. 2004. New vision for space exploration program. Available at <http://history.nasa. gov/Bush\%2 0.SEP . htm>. [accessed July 12, 2006].

Cates, G. R., and M. Mollaghasemi. 2005a. A discrete event simulation model for assembling the international space station. Proceedings of the 2005 Winter 
Simulation Conference, Orlando, Florida. Piscataway, New Jersey: Institute of Electrical and Electronics Engineers.

Cates, G. R., and M. Mollaghasemi. 2005b. Supporting the vision for space with discrete event simulation. Proceedings of the 2005 Winter Simulation Conference, Orlando, Florida. Piscataway, New Jersey: Institute of Electrical and Electronics Engineers.

Gehman, H. S. Turcotte, J. L. Barry, W. Hess, J. N. Hallock, S. B. Wallace, and D. Deal. 2003. Columbia accident investigation board (CAIB)-final report. Washington, D.C. US Government Accounting Office.

Rogers, W., N. A. Armstrong, D. C. Acheson, E. E. Covert, R. P. Feynman, R. B. Hotz, D. J. Kutyna, S. K. Ride, R. W. Rummel, J. F. Sutter, A. B. Walker, A. D. Wheelon, C. Yeager, and A. G. Keel. (1986). Report of the presidential commission on the space shuttle challenger accident. Washington, D.C.: US Government Accounting Office.

Seila, A. F. 2005. Spreadsheet simulation. Proceedings of the 2005 Winter Simulation Conference, Orlando, Florida. Piscataway, New Jersey: Institute of Electrical and Electronics Engineers.

\section{BIOGRAPHY}

MICHAEL G. MADDEN is a Ph.D. Student in the University of Miami's Industrial Engineering Program and a former Senior Vehicle Engineer for Space Shuttles Endeavour and Atlantis. He is also a Subject Matter Expert (SME) in the OPF processing of Space Shuttles. His subject matter expertise is derived from the 20 plus years of experience working as Senior Vehicle Engineer with the Space Shuttle processing team and test team responsible for making and processing technical decisions to ready the craft for each flight. He now works in the Florida Program Office of United Space Alliance, LLC, developing simulation technology for estimation of Space Shuttle processing flows, and on the new Crew Exploration Vehicle program for Moon, Mars, and Beyond. He has a M.S. in Technology Management from Embry-Riddle Aeronautical University, and a B.S.-Mech. ET from Wentworth Institute of Technology in Boston, MA. His research interests are in scheduling and other operations research problems associated with Shuttle processing and knowledge management. $\mathrm{He}$ is a member of the INFORMS Simulation Society, ACGIH, IEEE, and AIChE. 